\title{
A Framework For Discussing Ethics In Principles Of Accounting
}

Jeanne M. David, University of Detroit Mercy, USA

Patrick T. Wirtz, University of Detroit Mercy, USA

\begin{abstract}
The main focus of the discussion in this paper is on the principles or introductory level of accounting and is applicable for all students in the class, but much of its content is equally applicable to upper level accounting classes and our accounting majors. Early and Kelly (2004) and Clikeman (2003) support the value of ethics education in heightening a student's moral reasoning skills. "The goals of ethics education are creating an awareness of ethical dilemmas and providing methods of resolution." (Haas 2005)
\end{abstract}

\section{INTRODUCTION}

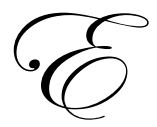

thics education continues to play an important part in accounting education. Its role has only increased in the years subsequent to the accounting debacles of Enron, Arthur Andersen, and other firms. As accounting educators, we are responsible for educating the next generation of accounting professionals. More so, as accounting educators, we have the opportunity to touch upon and help to build the ethical decision making skills of many of the business students who pass through our classes. We should strive to ensure that those leaving our institutions will bring with them the highest ethical and moral standards. Only in striving for this, can we move toward reestablishing the dignity once afforded to our profession.

The main focus of the discussion in this paper is on the principles or introductory level of accounting and is applicable for all students in the class, but much of its content is equally applicable to upper level accounting classes and our accounting majors. Early and Kelly (2004) and Clikeman (2003) support the value of ethics education in heightening a student's moral reasoning skills. "The goals of ethics education are creating an awareness of ethical dilemmas and providing methods of resolution." (Haas 2005) Furthermore, Armstrong (1993) argues, and the authors agree, that ethics should ideally be taught with a sandwich approach. This involves introducing the students to a course in ethics, preferably through a liberal arts class, then incorporating ethical issues into the business and accounting classes, and following up with another ethics class specifically focusing on business. The first general ethics class will provide the students with a framework for recognizing ethical dilemmas and the tools for making good ethical choices. It is important that the students then use these tools in a variety of business settings, most specifically for our profession, in accounting decision making. Going one step even further, Mastracchio (2005) suggests that accounting education should include a liberal arts ethics class, a business ethics class, and finally an accounting ethics class.

In discussing ethics in accounting, the issue of fraud cannot be overlooked. Fraud often occurs when the three components of the well-known fraud triangle are present: pressure, opportunity to engage in fraud, and the ability to rationalize one's behavior. In addition, Albrecht proposed that there are nine additional factors that contribute to creating the "perfect fraud storm" including unachievable expectations of Wall Street analysts, greed, moral decay, and inadequate education about ethics and fraud (Birchfield 2004). Although fraud and other illegal acts are certainly of concern, students must be advanced beyond the point of simply 'following the rules' to 'making good ethical decisions'. Pincus (2000) advocates moving students from a simple rule-based accounting approach to one that is principles-based. 


\section{ETHICS IN THE PRINCIPLES OF ACCOUNTING CLASSES}

If early accounting classes minimize the ethical focus or treat the subject with a tunnel-vision approach, business and our accounting students will tend to follow this thinking in later classes and beyond. They may not utilize the tools that they acquired in a general ethics program. Further, if the instructor does not challenge them to think out of the box, they will provide only simplified responses to "ethical problems" presented to them throughout the texts. Even if students have not been exposed to ethical decision making prior to taking introductory accounting, there are many ways the instructor can heighten their ability to recognize and successfully deal with ethical dilemmas. Doucet (1994) discusses the merits of virtue ethics and the importance of expertise, courage and integrity components in ethical decision making.

\section{SUPPLEMENTARY MATERIALS}

There are a multitude of materials available for the instructor to bring to the introductory accounting student. These materials range from videos and current news articles, vignettes and cases developed for the class, supplementary reading materials, and questionnaires that will help students evaluate their own ethical and moral standings. Thomas (2004) provides a detailed bibliography of materials suitable for use in a variety of accounting classes. Some of the bibliographic data is segregated by topic, such as integrity and professionalism, taxation, or management accounting. For example, Esmond-Kiger (2004) suggests having students write a series of three selfreflective essays which will "enhance the ethical awareness and sensitivity of students." Although students are not asked to make ethical decisions, they explicitly consider how actual examples from the press might impact their own lives and the profession. They evaluate their own values rankings, and consider how these might have evolved over the term as they become more exposed to these issues. Jennings (2004) provides her suggestion for required student readings including both the new and classical materials. She also distinguishes between the stakeholder model, social responsibility model and the moral code model approaches to ethics. Haywood, McMullen, and Wygal (2004) provide materials for a "bingo" game focusing on promoting adherence to a code of professional conduct. Their game centers on the codes of the AICPA, the IMA, and the IIA, and although probably best suited for an upper-level accounting course, it would certainly be amenable to an introductory level class. KMPG has a program entitled "The Ethical Compass" which is available for use in classes. "It consists of videos, case studies, and role plays designed to get students engaged in a thought process about the kinds of ethical choices they will have to make when presented with very specific scenarios in the workplace." (McCann 2007)

A decade or two ago, it was not uncommon to find principles of accounting textbooks that did not specifically address ethical problems. In the early chapters, professional organizations would be introduced, such as the AICPA, IMA, and/or IIA, and authors would indicate that these organizations had their own code of professional ethics. We assumed that those interested in the accounting profession had and would maintain high professional ethical standards. As there was more discussion about explicitly including ethics within the study of accounting, textbook authors have been exemplary in incorporating ethical decision making issues into most all chapters of their books. Now, it is the exception rather than the rule, if a chapter's assignment section contains nothing on ethics.

\section{CONSIDER THE ETHICAL ISSUE AT A NUMBER OF LEVELS}

Given the expanded level of ethics coverage in the typical accounting textbook, instructors should have no difficulty bringing ethics discussions to the classroom. Often, however, without further expanding on the discussion questions provided, those discussions can be very short and dry and decline to a level of "Is it GAAP or not?" Especially at this introductory level when students are just learning the rules, it becomes too easy to let the issues degenerate to a GAAP issue or a legal issue. Without causing the students to refocus the discussion, they leave with the impression that accounting is simply "walking the line". As long as things are within the rules, it is okay. This is the type of thinking that can lead future young professionals into making poor choices. It may very well be an appropriate attitude for taxation compliance questions, but it may be a very poor posture to take for a full disclosure issue. 
So, at what level do we challenge our students to think?

- $\quad$ There are legal issues. Is something allowable according to the law or not? Consider the state or country of origin. Copyrights and patents are protected under U.S. law, but that protection may not be granted to the firm elsewhere in the global economy.

- $\quad$ There are basic accounting principles, U.S. GAAP or other appropriate model, that should be followed. Principles of accounting students are learning these "rules" and may feel some difficulty in responding to ethical situations presented in the text because they are not sure that they understand these rules yet. Once they understand these rules, then the "answer" to the ethical issue should be clean and simple. Unfortunately, most instructors are well aware that this is an oversimplification and the real world is simply not that way.

- $\quad$ Professionalism in accounting is another level of analysis. Here, the student can be asked to consider the integrity, objectivity, confidentiality, and/or independence. Auditing courses will usually cover many of these issues, but students should be encouraged to start thinking about these things very early in their academic careers. The non-accounting, business students in the class will come to see the higher expectations surrounding the field of accounting. Introductory accounting students will see that accounting is more than just following the "rules".

- $\quad$ Another level is the social responsibility model. Jennings (2004) describes this model as educating students in "the importance of environmentalism, diversity, human rights, and philanthropy." Product liability issues and pollution can be viewed from a broader perspective rather than considering simply if the " $\mathrm{t}$ 's" have been crossed and the "i's" have been dotted. The student focus is drawn away from whether the legal minimums have been met.

- $\quad$ The stakeholder model requires students to identify various stakeholders or groups of stakeholders. Stakeholder groups may include owners, employees, or customers, to name a few. In some cases, it will be advantageous to consider subsets of these stakeholder groups. Often, individual employees or members of management should be considered. Some stakeholder groups may be more or less important to the individual issue at hand, but having the students identify these groups will be the first step in reflecting on their relevance to the problem. In analyzing the situation, the student would evaluate the impact of the decision on these various groups. Many of the ethics problems presented in introductory level texts ask the students to identify the stakeholders.

- $\quad$ Further analysis will move the student into the depths. The true ethicist will argue that determining the legality of an action, or its correctness according to a set of rules is not ethical decision making. Ethical decision making occurs when there is an ethical dilemma underlying the issue. A dilemma exists when the student must choose between actions which may benefit some but harm others or actions which may harm or benefit multiple groups but to varying extents. Ethical theories such as distributive justice, rights and duties, or virtue ethics can help guide the decision.

\section{EXPLOITING THE TEXTBOOK ETHICS PROBLEMS}

What can the instructor do at the simplest level to move the students toward thinking more ethically? How can we help prepare our students to be better ethical and moral decision makers? Often, simply expanding on the ethics problems already provided by the textbook authors can provide a rich basis for discussing ethical issues with the students. Two examples will be used to illustrate additional questions that may be posed to the class to enrich the ethics problem/issue provided in the text. The textbooks and problems used in these illustrations were not selected for any particular reason, and are not intended to critique the work of those authors. In fact, we found a rich variety of ethical problems throughout the introductory level accounting textbooks.

\section{Illustration 1:}

Python.com owes $\$ 6$ million on notes payable that will come due for payment in $\$ 1.5$ million annual installments. The company has used its cash to advertise heavily in the competitive dotcom business environment. The result is that cash is scarce, and Python.com has prepared its balance sheet at December 31, 20X4, and it reports the following. 


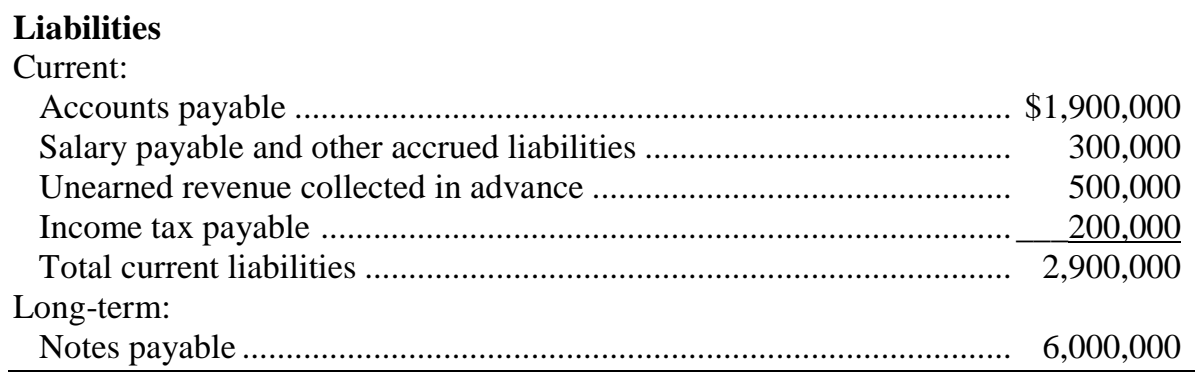

What is wrong with the way Python.com reported its liabilities? Why did Python.com report its liabilities this way? What is unethical about this way of reporting these liabilities? Who can be harmed? (Horngren, Harrison, Jr., and Bamber 2005, p. 614-615)

From the GAAP perspective, Python.com has misclassified its current and long term liabilities. Discourage the simple answer: GAAP has not been followed; Python.com does not want to look like it may liquidity problem; it is not ethical for the accountant to fail to apply GAAP; finally, readers of the statement do not get the proper picture of Python.com's financial position. Consider other potential questions:

- Legally, could there be potential ramifications for the accountant who has not followed GAAP in this case?

- What if the firm did not present a classified balance sheet and did not segregate its current and long term liabilities?

- What is the accountant's responsibility for disclosing both good and bad information? Is the accountant's integrity compromised in any way by using the above presentation?

- Is the information, presented as it is, objective? Does it fairly represent the financial position of the firm? How would your answer change if the balance sheet is not classified into current and long term accounts?

- How will each stakeholder or stakeholder group be impacted by this disclosure? Consider the holder of the note itself? Python.com's other creditors? New potential creditors? Python.com's shareholders? Its management? New potential investors in its stock?

- What is the accountant's responsibility to the public to present information objectively?

- Does this presentation disadvantage some group or groups to the benefit of others?

Illustration 2:

BYP8-10 The controller of Zapatos Corporation believes that the company's yearly allowance for doubtful accounts should be $2 \%$ of net credit sales. The president of Zapatos Corporation, nervous that the stockholders' might expect the company to sustain its $10 \%$ growth rate, suggests that the controller increase the allowance for doubtful accounts to $4 \%$. The president thinks that the lower net income, which reflects a $6 \%$ growth rate, will be a more sustainable rate for Zapatos Corporation.

Instructions

(a) Who are the stakeholders in this case?

(b) Does the president's request pose an ethical dilemma for the controller?

(c) Should the controller be concerned with Zapatos Corporation's growth rate in estimating the allowance? Explain your answer. (Kimmel, Weygandt, and Kieso 2004, p. 409)

Move beyond identifying the stakeholders and the viewpoints of the president and the controller.

- $\quad$ How will reporting only the $2 \%$ allowance, and resulting $10 \%$ growth rate, be viewed by the market? What potential impact may this have on the current stock price? What would the $4 \%$ allowance do? 
- What if the firm fails to maintain the $10 \%$ growth rate next period and had reported only the $2 \%$ allowance. How will this be viewed by the market? How would the firm look if they had reported the $4 \%$ allowance and then failed to maintain the $10 \%$ growth rate?

- What are some alternative courses of action that the controller might take in this situation? What are the potential consequences of each of these actions?

- If the controller decides that proper full and fair disclosure is achieved by reporting the $2 \%$, in contrast to the president's directive, how should the controller approach this disagreement with the president? What might you suggest that would promote a peaceful resolution to the issue without "giving in" to the president?

- $\quad$ Consider the relative wealth of both a current shareholder, and one who invests subsequent to this report. How will wealth shift between the parties if Zapatos reports the $2 \%$ allowance? The $4 \%$ allowance?

- Move to the broader question of whether the controller should be concerned with the growth rate in estimating the allowance. Should this be a general practice for all firms, and potentially considered in establishing GAAP?

- What is the impact to society in general if recognizing bad debts was conditioned upon its impact to the bottom lines of the income statement and/or balance sheet?

- What would happen if all accounting estimates were determined substantially or at least in part based upon their impact on the overall financial picture of the firm? Would this lead to income smoothing?

The first illustration provided an example of a simple misapplication of GAAP in classifying liabilities as current and long term and the second illustration was more subjective in nature, touching on the issue of estimating the allowance for doubtful accounts. Yet both provide the background for a rich discussion of ethical issues.

\section{EXPANDING THE DISCUSSION}

It is not necessary to touch on all areas for each ethical discussion in a particular class, but rather to provide students with a variety of approaches for viewing the dilemma at hand. In some situations, we can look at the legal issues and the accounting principles involved. Other times, professionalism and the implications for society might be at issue. We can challenge our students to consider the underlying assumptions and to view the situation from different perspectives. Role plays can be used in class. Online discussion boards can facilitate a continuing discussion and allow the instructor to intercede with alternative scenarios. Students must be challenged to suggest multiple potential solutions and then to evaluate the implications of these courses of action. We can expand their span of vision by requiring that they explicitly deliberate anticipated consequences to various stakeholders.

\section{CONCLUDING REMARKS}

Students taking principles of accounting may not yet possess the expertise needed to always make good ethical choices when accounting issues are involved. As they continue on in their accounting education, this expertise will develop. It is precisely because of the lack of refined accounting skills that they should all the more be challenged to make good ethical decisions involving accounting issues. Ethics is far more than just walking that straight line and not crossing over to the wrong side. Ethics is far more than simply keeping things legal and following GAAP or GAAS as the case may be. Doucet and Ruland (1994) discuss the merits of virtue ethics and the importance of expertise, courage and integrity components in ethical decision making. They state that virtue expertise, virtue courage and virtue integrity are all necessary components. Perhaps this is the other side of the fraud triangle that had gained such popularity.

Since beginning accounting students are weak in the area of expertise, by emphasizing courage and integrity in their decision making, we will move them beyond just looking at the rules. As they gain proficiency in accounting, we must continually challenge them to examine their decisions in light of all three components. We must not let them slide down the trough of simply following rules of accounting without considering the principles at hand and the ethics involved. If we do not progress in educating our students in the area of ethics and accounting, it is our profession that will suffer. "The more knowledge we have, the less we are likely to let outside influences control our choices. It gives us the freedom to make decisions based on our personal convictions and sense of integrity and ethics." (Business \& Finance Magazine 2007) We can empower our students with that knowledge and 
courage needed to make good ethical choices as they move through their journey from education into the workforce. We can give them a view of our world that looks beyond the "me" to see the good that they can accomplish for their families, their firms, their society and ultimately, their world.

\section{REFERENCES}

1. $\quad$ Armstrong, M. B. 1993. "Ethics and Professionalism in Accounting Education: A Sample Course.” Journal of Accounting Education 11: 77-92.

2. $\quad$ Birchfield, Reg. "Ethics: Fraud and the Family." New Zealand Management (September 2004): 39-40.

3. $\quad$ Business \& Finance Magazine. "The Power of Education." Business \& Finance Magazine (July 27, 2007): 82-84.

4. $\quad$ Clikeman, Paul M. "Educating for the Public Trust.” CPA Journal 73:8 (September 2003): 80.

5. Doucet, M. S., and Ruland, R. G. "An Exploration of the Professional Role: Necessary Virtues for the Public Accountant." Newsletter of the Public Interest section of the American Accounting Association, A Special Issue on Ethics in Accounting 19 (April): 7, 10.

6. Early, Christine E., and Kelly, Patrick T. "A Note on Ethics Educational Interventions in an Undergraduate Auditing Course: Is There an 'Enron Effect'?” Issues in Accounting Education 19:1 (February 2004): 5371.

7. Esmond-Kiger, Connie. "Making Ethics a Pervasive Component of Accounting Education." Management Accounting Quarterly 5:4 (Summer 2004): 42f.

8. Haas, Amy. "Now Is the Time for Ethics in Education," CPA Journal 75:6 (June 2005): 66-68.

9. Haywood, M. Elizabeth, McMullen, Dorothy A., and Wygal, Donald E. "Using Games to Enhance Student Understanding of Professional and Ethical Responsibilities." Issues in Accounting Education 19:1 (February 2004): 85-99.

10. Horngren, Charles T., Harrison, Jr., Walter T., and Bamber, Linda Smith. Accounting, $6^{\text {th }}$ edition. Upper Saddle River, NJ: Prentice Hall 2005.

11. Jennings, Marianne M. "Incorporating Ethics and Professionalism into Accounting Education and Research: A Discussion of the Voids and Advocacy for Training in Seminal Works in Business Ethics," Issues in Accounting Education 19:1 (February 2004): 7-26.

12. Kimmel, Paul D., Weygandt, Jerry J., and Kieso, Donald E. Principles of Accounting: Tools for Business Decision Making. John Wiley \& Sons, Inc., 2004.

13. Mastracchio, Jr., Nicholas J. "Teaching CPAs About Serving the Public Interest." CPA Journal 75:1 (June 2005): 6,8f.

14. McCann, David. "KPMG Spreads the Ethics Gospel" cfo.com (November 29, 2007). http://www.cfo.com/article.cfm/10234252?f=search

15. Pincus, K. V. "The Role of Rules in Accounting: Do Rules Guide Us to the Right Path or to the Path of Least Resistance?" Research on Accounting Ethics 6 (2000): 243-258.

16. Thomas, C. William. "An Inventory of Support Materials for Teaching Ethics in the Post-Enron Era." Issues in Accounting Education 19:1 (February 2004): 27-52. 